\title{
The Children and Nature Connection: Why It Matters
}

Judy Braus ${ }^{1}$ and Sarah Milligan-Toffler ${ }^{2}$

${ }^{1}$ Executive Director, North American Association for Environmental Education, Washington, DC.

${ }^{2}$ Executive Director, Children \& Nature Network, Minneapolis, Minnesota.

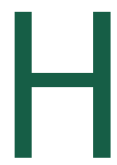

umans have always relied on nature for survival. Even in our modern urban environments, we continue to rely on nature for our most basic needs. But quietly, and under the radar of most people, over the past 30 years a deep connection to nature is being lost for many children.

Indigenous wisdom, science, philosophy, literature, and poetry from every culture tell us that a connection to the natural world can be essential for human prosperity-from sustaining livelihoods to sparking innovation and imagination (Schinz, 1929). We're also learning that it can inspire a lifelong appreciation that leads to a commitment to keep nature and natural resources healthy and plentiful (Wells \& Lekies, 2006). And we know that, for some, spending time in nature helps us feel that we are part of something much bigger than ourselves. Our connections to nature also support health and well-being, spur creativity, and build stewardship values (Kellert, 2012).

An increasing body of empirical research is showing that young people-starting from our earliest learners-who have regular experiences with nature, children who bond with nature, develop critical and creative thinking skills that will help them succeed in life (Adams \& Savahl, 2017). We're also learning that immersing children in nature to play and learn can result in reduced stress, improved brain development and restoration, increased social and emotional skills development, and civic engagement (Hartig, Mitchell, de Vries, \& Frumkin, 2014).

What's exciting is that researchers and practitioners around the world are working together to bridge the disconnect, uncovering more knowledge of the valuable and impactful ways nature affects our bodies, our brains, and our hearts. And we're realizing that there's no single way to most effectively connect with the natural world. This connection looks different across all parts of the world, in every corner of every community, and with every individual.

The papers in this special issue bring together several fields of study at the intersection of children, nature, education, and health and well-being. As we look to the fields of environmental education, ecopsychology, landscape architecture, child development, social and environmental justice, and environmental, indigenous, and urban studies, we are learning just how interconnected they are. We appreciate the opportunity to work with the editor of Ecopsychology, Peter Kahn, to explore the insights and intersections of these fields of study to better understand the relationship between connection to nature and all the benefits we reap as humans by spending time in nature.

As leaders of two organizations-the North American Association for Environmental Education (NAAEE) and the Children \& Nature Network (CEtNN)-that care deeply about these issues and about advancing our collective understanding of the importance of spending time in nature, we are so pleased to be the guest editors of this special issue, which explores this topic from a wide range of perspectives and ways of knowing. And we believe that collaboration among organizations, disciplines, and perspectives will help us all learn so much more.

Understanding the critical relationships between connections to nature formed (or not formed) in childhood is important to both of our organizations and the work we're doing to help support positive outcomes for children, youth, adults, and communities. Through the strengths and capacities of both NAAEE and CENN, we have been able to attract a wide variety of articles and points of view on this issue.

As we continue to learn more about connection to nature, it's evident how important collaboration is to our collective learning. And to help bridge the gap between research and practice, NAAEE and C\&NN spearheaded a collaborative effort to provide the field with access to research collected by both organizations. Together, we designed and launched eeRESEARCH-a new research library that includes more than 1,100 research summaries, syntheses, and full 


\section{BRAUS AND MILLIGAN-TOFFLER}

articles from both organizations related to environmental education, including connecting people to nature.

We look forward to continuing this collaboration around sharing, activating, driving, and expanding research for the field, and we eagerly anticipate hearing from you about how our organizations can help support new research, enhance efforts to use research to improve practice, and improve our understanding of why connection to nature might be more important than we ever imagined.

\section{REFERENCES}

Adams, S., \&t Savahl, S. (2017). Nature as children's space: A systematic review. The Journal of Environmental Education, 48, 291-321.

Hartig, T., Mitchell, R., de Vries, S., \&t Frumkin, H. (2014). Nature and health. Annual Review of Public Health, 35, 207-228.

Kellert, S. (2012). Building for life: Designing and understanding the human-nature connection. Washington, DC: Island Press.
Schinz, A. (1929). The concept of nature in philosophy and literature. Proceedings of the American Philosophical Society, 68, 207-225.

Wells, N. M., \& Lekies, K. S. (2006). Nature and the life course: Pathways from childhood nature experiences to adult environmentalism. Children, Youth and Environments, 16, 1-24.

Address correspondence to: Sarah Milligan-Toffler

Children \&t Nature Network

808 14th Ave $S$

Minneapolis, MN 55409

E-mail: sarah@childrenandnature.org

Received: October 28, 2018

Accepted: October 28, 2018 